\title{
Hyper-proteolytic mutant of Beauveria bassiana, a new biological control agent against the tomato borer
}

\author{
Ines Borgi $^{1}$ - Jean-William Dupuy ${ }^{2}$ - Imen Blibech ${ }^{3}$ • Delphine Lapaillerie ${ }^{2}$. \\ Anne-Marie Lomenech ${ }^{2} \cdot$ Ahmed Rebai $^{4}$ - Mohieddine Ksantini ${ }^{3}$ - Marc Bonneu ${ }^{2}$. \\ Ali Gargouri ${ }^{1}$
}

Accepted: 14 September 2016/Published online: 18 October 2016

(C) INRA and Springer-Verlag France 2016

\begin{abstract}
The world tomato production is threatened by the invasive tomato borer Tuta absoluta. Difficulties in managing this pest were imposed mainly by the development of resistance in strains treated with conventional chemical insecticides. Resistance problems were even reported to insecticides of natural origin, leading to search for other control alternatives. P2 is a spontaneous mutant of the entomopathogenic fungus Beauveria bassiana. It was previously selected from a local strain (P1) and was characterized as hyper-producer of extracellular proteases. Here, the insecticidal potential of P1 and $\mathrm{P} 2$ strains was evaluated against $T$. absoluta larvae under laboratory conditions. Both strains were effective but P2 showed stronger effect than P1; median lethal concentration of P2 is tenfold lower than that of P1. Enzymatic assay analysis showed that extracellular enzymes are differently expressed by the two strains, especially proteases and chitinases which are known as cuticle degrading enzymes.
\end{abstract}

Electronic supplementary material The online version of this article (doi:10.1007/s13593-016-0394-6) contains supplementary material, which is available to authorized users.

Ali Gargouri

faouzi.gargouri@cbs.rnrt.tn

1 Laboratoire de Biotechnologie Moléculaire des Eucaryotes, Centre de Biotechnologie de Sfax, University of Sfax, BP1177, 3018 Sfax, Tunisia

2 Centre de Génomique Fonctionnelle, Plateforme Protéome, Université de Bordeaux, 33000 Bordeaux, France

3 Unité de Protection des Plantes Cultivées et Environnement, Institut de l'olivier de Sfax, Route de l'Aéroport, B.P. 1087, 3000 Sfax, Tunisia

4 Laboratoire des Procédés de Criblage Moléculaire et Cellulaire, Centre de Biotechnologie de Sfax, University of Sfax, BP1177, 3018 Sfax, Tunisia
The major expressed subtilisin-like protease (SBP) was upregulated at the transcriptional level in P2 strain. Proteomic analysis revealed four SBP isoforms which are highly overexpressed in this strain compared to P1. Post-translational regulation, most probably phosphorylation, was further suggested to control the SBP protease expression in B. bassiana $\mathrm{P} 1$ and P2 strains. The enzymatic profile in the two strains might explain their different insecticidal potential against the tomato borer. This is the first report showing such efficiency of Beauveria strains against this dangerous pest. Particularly, P2 strain showed high virulence reaching almost total larval mortality within 5 days post-application. It thus should be recommended as a new tool for the biocontrol of T. absoluta.

Keywords Beauveria bassiana $\cdot$ Protease isoforms · Tuta absoluta $\cdot$ Biopesticide $\cdot$ Tomato borer $\cdot$ Biocontrol

\section{Introduction}

The tomato leaf miner, or tomato borer, Tuta absoluta (Meyrick) (Lepidoptera: Gelechiidae) is considered as one of the most damaging tomato pest. It originated in South America and has recently spread to Europe and North African countries. It leads to serious losses, affecting up to $100 \%$ of tomato crops (Campos et al. 2014; Pratissoli and Parra 2000). Larvae, which are the harmful stage, can feed on all parts of the plants (leaf, stem or fruit) and form mines within (Fig. 1). Several chemical insecticides such as abamectin, cartap and permethrin have been widely used against $T$. absoluta but later were abandoned because of widespread resistance (Siqueira et al. 2000). Other considerable problems were associated with the use of these conventional insecticides, such as environmental, ecological and human health effects. Furthermore, organically produced tomatoes 
Fig. 1 T. absoluta, a dangerous insect pest to tomato plants and fruit. Tomato leaf and fruit damages. Larvae feed on the leaf mesophyll, ripe and unripe fruit creating mines and holes (a). Signs of damage on the tomato plant. Clear patches appear on the leaves affecting the photosynthetic capacity of plants and later become necrotic resulting in a subsequent reduction in the crop yield (b)

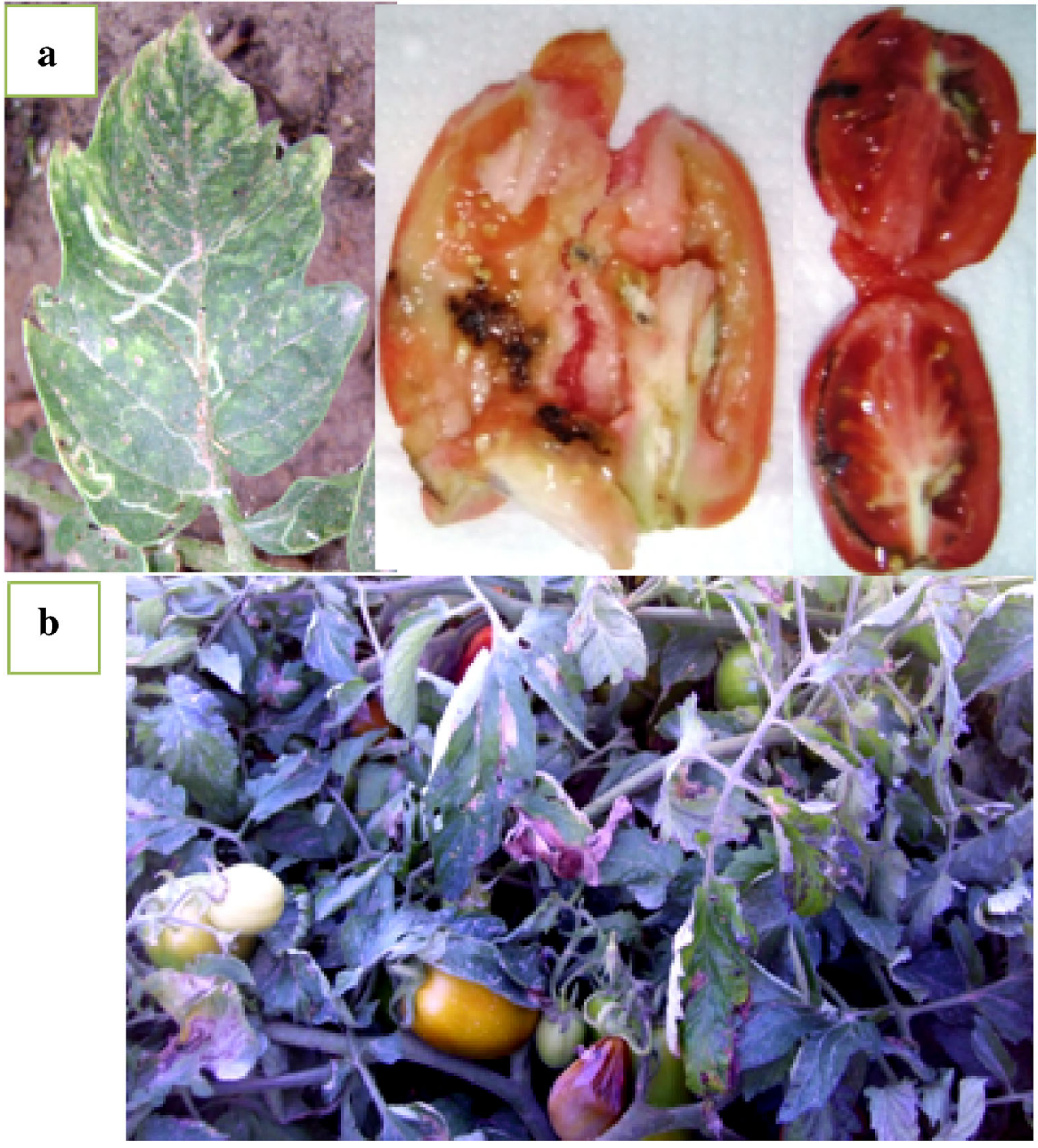

have been another factor leading to the use of bioinsecticides, mainly spinosad. However, reports of resistance counterpoint the potential for its further use (Campos et al. 2014). Another promising biocontrol strategy is the use of indigenous natural enemies. Various predators (i.e. Nesidiocoris tenuis, Mimulus pygmaeus) and parasitoids (i.e. Trichogramma achaea, Neochrysocharis formosa, Bracon sp.) species spontaneously attack T. absoluta in tomato crops worldwide. Some of these are already commercialized and have been employed successfully in integrated pest management strategies, i.e. the parasitoid T. achaea which is used by periodic inundative releases, individually and in association with mirid predators, i.e. M. pygmaeus and N. tenuis (Zappala et al. 2013). Bacillus thuringiensis is also efficient in controlling T. absoluta when pulverized in greenhouse and open-field tomato plants (González-Cabrera et al. 2011).

Entomopathogenic fungi are under intensive study since they are known to be non-toxic for animals and humans and to be safer for the environment than chemical products. They have been formulated for application in agricultural insect pest management systems with successful results.

The most common commercial mycoinsecticides and mycoacaricides on the market are based on Beauveria bassiana (33.9\%), Metarhizium anisopliae (33.9\%), Isaria fumosorosea (5.8\%) and Beauveria brongniartii (4.1\%) (Faria and Wraight 2007). These fungi infect the host insect by direct penetration of the insect cuticle which consists mainly of proteins and chitin, by producing extracellular enzymes directed to hydrolyse these cuticular components. Proteases and chitinases, which are the primary virulence determinants, were the most studied enzymes and their role in virulence is well documented (Fan et al. 2007; St. Leger et al. 1996). Furthermore, fungal virulence may attribute other factors and molecules including the hydrophobicity of conidia and the secretion of toxins (Ortiz-Urquiza et al. 2010). Few studies have investigated on the pathogenicity of Beauveria strains towards T. absoluta. Laboratory experiments showed that different isolates of this fungus, pulverized on eggs and larvae of 
the tomato borer, were more virulent to eggs (Pires et al. 2010). Higher virulence was found when the first instar larvae were treated with $M$. anisopliae, compared to B. bassiana strains. However, no total efficiency was found using any strain (Inanli et al. 2012; Pires et al. 2010). Better results were obtained when T. absoluta larvae were fed with leaves treated with $B$. bassiana (Giustolin et al. 2001; Shalaby et al. 2013), reaching $100 \%$ of total larval mortality (Klieber and Reineke 2015).

In this study, we evaluated two Tunisian strains of $B$. bassiana for their pathogenicity towards T. absoluta larvae. These strains, P1 and P2, were previously isolated and studied for their extracellular proteases production (Borgi and Gargouri 2014). Higher yields were found in $\mathrm{P} 2$, and the major expressed protease (subtilisin-like protease [SBP]), which is a serine subtilisin-like, was purified and the gene encoding this enzyme was sequenced (Borgi and Gargouri 2014). Here, the secretomes from both strains was compared via two-dimensional electrophoresis (2DE) coupled to mass spectrometry analysis. These strains were also used for the assays of cuticle degrading enzymes.

\section{Materials and methods}

\subsection{Chemical reagents}

All reagents and chemicals were obtained from either SigmaAldrich (USA/Steinheim, Germany), Biorad (München, Germany) or Amersham-Biosciences (Amersham, UK).

\subsection{Fungal strains}

B. bassiana $\mathrm{P} 1$ and $\mathrm{P} 2$ are laboratory strains, identified by sequencing the $18 \mathrm{~S}$ ribosomal ribonucleic acid (rRNA) genes and comparing sequences with GenBank database via Blast (https://blast.ncbi.nlm.nih.gov/Blast.cgi). Identification was confirmed by the "Centraal Bureau voor Schimmelculture" of Holland (Borgi and Gargouri 2014). The P1 wild-type strain was deposited in the National Collection of Microorganisms of the Center of Biotechnology of Sfax (Tunisia) under the reference CTM10549 P1.

B. bassiana strains (P1 and P2) were cultured on Luria Bertani solid medium ( $5 \mathrm{~g} \mathrm{NaCl}, 10 \mathrm{~g}$ bacto-peptone, $5 \mathrm{~g}$ yeast extract, $17 \mathrm{~g}$ agar and 11 distilled water) at $30^{\circ} \mathrm{C}$ for 12 days before being used in experiments. Aerial conidia were harvested in distilled water supplemented with $0.1 \%$ Tween 80 , filtered and counted using a haemocytometer. The filtrates were centrifuged, and the final concentrations were adjusted to $10^{9}$ conidia/ml in the sterile water supplemented with glycerol $10 \%$.

\subsection{Bioassays with $T$. absoluta larvae}

A laboratory colony of $T$. absoluta was established from a Tunisian tomato field. This colony was maintained on tomato plants which were placed in pots and held in rearing plastic cages $(50 \mathrm{~cm} \times 50 \mathrm{~cm} \times 50 \mathrm{~cm})$ under laboratory conditions $\left(25 \pm 3{ }^{\circ} \mathrm{C}, 60 \pm 5 \%\right.$ relative humidity with a natural photoperiod of $\sim 16 \mathrm{~h}$ light $/ 8 \mathrm{~h}$ dark). Emerged adults from pupae were fed on $10 \%$ honey solution and tomato terminal buds and fresh leaves. After oviposition, T. absoluta larvae were used in the bioassays.

Ten conidial suspensions of Beauveria strains P1 and P2 $\left(10^{2}\right.$ to $10^{9}$ conidia $/ \mathrm{ml}$ ) were prepared by serial dilution and used for infection. Each suspension was spread onto larvae (second to fourth larval instars), resulting in $10 \mu \mathrm{l}$ of conidial suspension/ larvae. Control larvae were treated with sterile $\mathrm{H}_{2} \mathrm{O}$. For each experimental condition, 30 larvae were used. Each 10 larvae were transferred in individual Petri dishes containing $10 \%$ honey solution and fresh leaves and incubated in an incubator at $26 \pm 0.5{ }^{\circ} \mathrm{C}$ and $72 \pm 5 \%$ relative humidity with a natural photoperiod of $\sim 16 \mathrm{~h}$ light $/ 8 \mathrm{~h}$ dark. The number of dead larvae was recorded daily. All experiments were repeated three times.

\subsection{Enzyme production and assays}

Hydrolytic enzymes were produced on modified Mandels liquid medium (Borgi and Gargouri 2014), supplemented with $1 \%$ of skimmed milk. Cultures were inoculated with $10^{7}$ conidia $/ \mathrm{ml}$ of P1 or P2 strain and incubated at $30{ }^{\circ} \mathrm{C}$ and $150 \mathrm{rpm}$. After different incubation times, cultures media were centrifuged at $6000 \mathrm{~g}$ for $10 \mathrm{~min}$ at room temperature and the supernatants were used for the assays as follows.

Protease activity was measured by the method of Kembhavi et al. (1993) using casein as substrate. One unit of protease activity was defined as the amount of enzyme required to liberate $1 \mu \mathrm{g}$ tyrosine $/ \mathrm{ml}$ in $1 \mathrm{~min}$ at $\mathrm{pH} 8$ and $60^{\circ} \mathrm{C}$.

Chitinase activity assay was performed as previously described (Kim and Yang 2003). One unit of chitinase activity was defined as the amount of enzyme that released sugars equivalent to $1 \mathrm{~mol}$ of $\mathrm{N}$-acetylglucosamine per hour at $\mathrm{pH} 5$ and $50{ }^{\circ} \mathrm{C}$.

$\beta$-Glucosidase was assayed with $p$-nitrophenyl- $\beta$-Dglucopyranoside (pNPG; Sigma) according to Saibi and Gargouri (2011), with one unit of activity being the amount of enzyme required to produce $1 \mu \mathrm{mol}$ of $p$-nitrophenol per minute at $\mathrm{pH} 5$ and $60^{\circ} \mathrm{C}$.

$\beta$-galactosidase activity was monitored by measuring the increase in glucose concentrations over time using lactose as substrate at pH 6 and $60^{\circ} \mathrm{C}$ (Nguyen et al. 2006). The glucose formed in the reaction was determined as described by Kunst et al. (1988). One unit of activity corresponds to the amount of enzyme that liberates $1 \mu \mathrm{mol}$ of glucose per minute in the reaction conditions.

\subsection{Two-dimensional electrophoresis}

Six-day cultures were used to analyse extracellular proteins from P1 and P2 strains. Two hundred microgrammes of the extracellular supernatants (filtered through a $0.45-\mu \mathrm{m}$ filter) was loaded on isoelectro focussing strips with a non-linear gradient of 
ampholytes ranging from $\mathrm{pH} 3$ to 10 using the isoelectro focussing cell system. After the IEF process, the strips were run in SDS-PAGE according to Laemmli (1970). Gels were stained with colloidal Coomassie blue G250. Gels were scanned using the GS800 imaging densitometer (Bio-Rad) and analysed using the PDQuest software (version 8.0.1; Bio-Rad). Proteins making difference between P1 and P2 in 2-D profiles were manually excised. This experiment was repeated three times.

\subsection{Protein identification by mass spectrometry}

Spots were destained in $25 \mathrm{mM}$ ammonium bicarbonate $\left(\mathrm{NH}_{4} \mathrm{HCO}_{3}\right), 50 \%(v / v)$ acetonitrile $(\mathrm{ACN} ; \mathrm{VWR}$ Chemicals) and shrunk in ACN for 10 min. After ACN removal, gel pieces were dried at room temperature. Proteins were digested by incubating each gel slice with $10 \mathrm{ng} / \mu \mathrm{l}$ of trypsin (T6567, Sigma-Aldrich) in $40 \mathrm{mM} \mathrm{NH}_{4} \mathrm{HCO}_{3}, 10 \%$ $(v / v) \mathrm{ACN}$; rehydrated at $4{ }^{\circ} \mathrm{C}$ for $10 \mathrm{~min}$; and finally incubated overnight at $37^{\circ} \mathrm{C}$. The resulting peptides were extracted from the gel in three steps: a first incubation in $40 \mathrm{mM}$ $\mathrm{NH}_{4} \mathrm{HCO}_{3}, 10 \%(v / v) \mathrm{ACN}$ for $15 \mathrm{~min}$ at room temperature and two incubations in $47.5 \%(v / v) \mathrm{ACN}$ and $5 \%(v / v)$ formic acid (Sigma) for $15 \mathrm{~min}$ at room temperature. The three collected extractions were pooled with the initial digestion supernatant, dried in a vacuum centrifuge (SpeedVac; Eppendorf) and resuspended with $25 \mu \mathrm{l}$ of $0.1 \%(v / v)$ formic acid before performing the nano-LC-MS/MS analysis.

Peptide mixtures were analysed by online capillary nanoHPLC (LC Packings, Amsterdam, The Netherlands) coupled to a nano-spray LCQ Deca XP ion trap mass spectrometer (ThermoFinnigan, San Jose, CA, USA). Ten microlitres of each peptide extract were loaded on a $300 \mu \mathrm{m}$ ID $\times 5 \mathrm{~mm}$ PepMap C18 precolumn (LC Packings, Dionex, USA) at a flow rate of $20 \mu \mathrm{l} / \mathrm{min}$. After 5 min desalting, peptides were online separated on a $75 \mu \mathrm{m}$ internal diameter $\times 15 \mathrm{~cm} \mathrm{C18}$ PepMapTM column (LC Packings, Amsterdam, The Netherlands) with a 5-40\% linear gradient of solvent B in 48 min (solvent A was $0.1 \%(v / v)$ formic acid in $5 \%(v / v)$ ACN, and solvent B was $0.1 \%(v / v)$ formic acid in $80 \%(v / v)$ ACN). The separation flow rate was set at $200 \mathrm{nl} / \mathrm{min}$. The mass spectrometer operated in positive ion mode at a $1.8-\mathrm{kV}$ needle voltage and a $4-\mathrm{V}$ capillary voltage. Data acquisition was performed in a data-dependent mode alternating in a single run, an MS scan survey over the range $m / z, 300-1700$ and three MS/MS scans with collision induced dissociation (CID) as activation mode. MS/MS spectra were acquired using a 2$\mathrm{m} / \mathrm{z}$ unit ion isolation window, a $35 \%$ relative collision energy and a 0.5 min dynamic exclusion duration.

Mascot, MS Amanda and Sequest algorithms through Proteome Discoverer 1.4 Software (Thermo Fisher Scientific Inc., USA) were used for protein identification against the UniProt B. bassiana database (http://www.uniprot. org/taxonomy/176275;22,152 entries). Two missed enzyme cleavages were allowed. Mass tolerances in MS and MS/MS were set to 2 and $1 \mathrm{Da}$, respectively. Oxidation of methionine, deamidation of asparagine and glutamine and acetylation of lysine and protein $\mathrm{N}$-terminus were searched as dynamic modifications. Carbamidomethylation on cysteine was searched as static modification. Peptide validation was performed using Target Decoy PSM Validator, and only "high confidence" peptides were retained corresponding to a $1 \%$ false positive rate at peptide level. The mass spectrometry proteomics data have been deposited to the ProteomeXchange Consortium (Vizcaín et al. 2014) via the PRIDE partner repository (http://www.ebi.ac.uk/pride/help/archive/about) with the dataset identifier PXD003287. Identification results are presented in supplementary data 1.

\subsection{Statistical analysis}

SPSS version 16.0 for Windows was used for all statistical analysis (SPSS Inc. 2008, USA). Cumulative larval mortality was corrected for natural mortality using Abbott's formula (Abbott 1925). Larval mortality and enzyme production data were statistically analysed using repeated measure ANOVA and the general linear model (GLM). Means were separated by Tukey's HSD test $(p=0.05)$. The median lethal concentration and time values were calculated using the Probit analysis.

\section{Results and discussion}

\subsection{Evaluation of P1 and P2 strains for their virulence against T. absoluta}

The tomato leafminer, T. absoluta, is a major pest insect which attacks solanaceous crops. Chemical control failed to overcome this pest because of resistance development, the minefeeding behaviour of larvae and deficient spraying technology (Siqueira et al. 2000). In the search for other pest management, mycoinsecticides are an important tool among the new alternatives to be considered.

In this study, two strains $\mathrm{P} 1$ and $\mathrm{P} 2$ of $B$. bassiana were evaluated for their virulence towards T. absoluta larvae, under laboratory conditions. Larvae were chosen for treatments since it is the damaging stage affecting all parts of plant especially fruits. Bioassays were performed by topical application which is the conventional method used in biological control applications.

Different concentrations of both strains conidia were tested on the daily larval mortality of T. absoluta (Table 1). Larval mortality caused by each strain increased proportionally with conidia concentration and time post-applications. Repeated measures ANOVA analysis showed a significant difference among treatments (at all concentrations) over the whole period of bioassay $(F=74.9$; df $=1.51 ; p<0.001)$. At each 
Table 1 Cumulative percentage mortality of $T$. absoluta larvae treated with different concentrations of $B$. bassiana $\mathrm{P} 1$ and $\mathrm{P} 2$ conidia after different incubation times

\begin{tabular}{|c|c|c|c|c|c|c|c|}
\hline \multirow[t]{2}{*}{ Treatment } & \multirow{2}{*}{$\begin{array}{l}\text { Concentration } \\
\text { (conidia/ml) }\end{array}$} & \multicolumn{4}{|c|}{ Time after the application } & \multirow{2}{*}{$\begin{array}{l}F \\
(\mathrm{df}=1.4)\end{array}$} & \multirow{2}{*}{$\begin{array}{l}p \\
\text { value }\end{array}$} \\
\hline & & 1 day & 2 days & 3 days & 5 days & & \\
\hline Control (water) & - & $5 \mathrm{a}$ & $6 a$ & $7 \mathrm{a}$ & $8 \mathrm{a}$ & - & - \\
\hline $\begin{array}{l}\text { P1 } \\
\text { P2 }\end{array}$ & $10^{2}$ & $\begin{array}{l}0 \mathrm{a} \\
0 \mathrm{a}\end{array}$ & $\begin{array}{l}0 \mathrm{a} \\
0 \mathrm{a}\end{array}$ & $\begin{array}{l}0 \mathrm{a} \\
6.4 \mathrm{a}\end{array}$ & $\begin{array}{l}0 \mathrm{a} \\
13 \mathrm{a}\end{array}$ & 15.974 & 0.016 \\
\hline $\begin{array}{l}\text { P1 } \\
\text { P2 }\end{array}$ & $10^{3}$ & $\begin{array}{l}4.2 \mathrm{a} \\
8.4 \mathrm{a}\end{array}$ & $\begin{array}{l}5.3 \mathrm{a} \\
19.1 \mathrm{a}\end{array}$ & $\begin{array}{l}4.3 \mathrm{a} \\
24.7 \mathrm{a}\end{array}$ & $\begin{array}{l}5.4 \mathrm{a} \\
30.4 \mathrm{a}\end{array}$ & 27.622 & 0.006 \\
\hline $\begin{array}{l}\mathrm{P} 1 \\
\mathrm{P} 2\end{array}$ & $10^{4}$ & $\begin{array}{l}12.6 \mathrm{~b} \\
31.5 \mathrm{~b}\end{array}$ & $\begin{array}{l}14.8 \mathrm{~b} \\
35.1 \mathrm{~b}\end{array}$ & $\begin{array}{l}23.6 \mathrm{~b} \\
41.9 \mathrm{~b}\end{array}$ & $\begin{array}{l}29.3 \mathrm{~b} \\
48.9 \mathrm{~b}\end{array}$ & 33.158 & 0.005 \\
\hline $\begin{array}{l}\mathrm{P} 1 \\
\mathrm{P} 2\end{array}$ & $10^{5}$ & $\begin{array}{l}25.2 \mathrm{c} \\
50.5 \mathrm{c}\end{array}$ & $\begin{array}{l}35.1 \mathrm{c} \\
56.3 \mathrm{c}\end{array}$ & $\begin{array}{l}39.7 \mathrm{c} \\
63.4 \mathrm{c}\end{array}$ & $\begin{array}{l}47.8 \mathrm{c} \\
69.5 \mathrm{c}\end{array}$ & 10.033 & 0.034 \\
\hline $\begin{array}{l}\text { P1 } \\
\text { P2 }\end{array}$ & $10^{6}$ & $\begin{array}{l}45.2 \mathrm{~cd} \\
60 \mathrm{~cd}\end{array}$ & $\begin{array}{l}48.9 \mathrm{~cd} \\
72.3 \mathrm{~cd}\end{array}$ & $\begin{array}{l}56.9 \mathrm{~cd} \\
77.4 \mathrm{~cd}\end{array}$ & $\begin{array}{l}68.4 \mathrm{~cd} \\
76 \mathrm{~cd}\end{array}$ & 18.881 & 0.012 \\
\hline $\begin{array}{l}\text { P1 } \\
\text { P2 }\end{array}$ & $6.10^{6}$ & $\begin{array}{l}54.2 \mathrm{de} \\
68.4 \mathrm{de}\end{array}$ & $\begin{array}{l}51 \mathrm{de} \\
74.4 \mathrm{de}\end{array}$ & $\begin{array}{l}59.1 \mathrm{de} \\
86 \mathrm{de}\end{array}$ & $\begin{array}{l}68.4 \mathrm{de} \\
90.2 \mathrm{de}\end{array}$ & 24.814 & 0.008 \\
\hline $\begin{array}{l}\mathrm{P} 1 \\
\mathrm{P} 2\end{array}$ & $10^{7}$ & $\begin{array}{l}\text { 53.6def } \\
\text { 69.4def }\end{array}$ & $\begin{array}{l}\text { 63.8def } \\
76.5 \mathrm{def}\end{array}$ & $\begin{array}{l}\text { 74.1def } \\
82.7 \mathrm{def}\end{array}$ & $\begin{array}{l}\text { 82.6def } \\
\text { 91.3def }\end{array}$ & 64.204 & 0.001 \\
\hline $\begin{array}{l}\mathrm{P} 1 \\
\mathrm{P} 2\end{array}$ & $6.10^{7}$ & $\begin{array}{l}63.1 \mathrm{ef} \\
74.7 \mathrm{ef}\end{array}$ & $\begin{array}{l}68 \mathrm{ef} \\
84 \mathrm{ef}\end{array}$ & $\begin{array}{l}76.3 \mathrm{ef} \\
93.5 \mathrm{ef}\end{array}$ & $\begin{array}{l}79.3 \mathrm{ef} \\
96.7 \mathrm{ef}\end{array}$ & 11.239 & 0.029 \\
\hline $\begin{array}{l}\mathrm{P} 1 \\
\mathrm{P} 2\end{array}$ & $8.10^{8}$ & $\begin{array}{l}65.2 \mathrm{f} \\
86.3 \mathrm{f}\end{array}$ & $\begin{array}{l}75.5 \mathrm{f} \\
92.5 \mathrm{f}\end{array}$ & $\begin{array}{l}80.6 \mathrm{f} \\
97.8 \mathrm{f}\end{array}$ & $\begin{array}{l}86.9 f \\
98.9 f\end{array}$ & 15.662 & 0.017 \\
\hline $\begin{array}{l}\text { P1 } \\
\text { P2 }\end{array}$ & $10^{9}$ & $\begin{array}{l}64.2 \mathrm{f} \\
84.2 \mathrm{f}\end{array}$ & $\begin{array}{l}73.4 \mathrm{f} \\
91.4 \mathrm{f}\end{array}$ & $\begin{array}{l}86 \mathrm{f} \\
93.5 \mathrm{f}\end{array}$ & $\begin{array}{l}91.3 \mathrm{f} \\
96.7 \mathrm{f}\end{array}$ & 32.897 & 0.005 \\
\hline
\end{tabular}

Results are means of three replicates for each conidial concentration. Cumulative mortality data were corrected using Abbott's formula. Means in a line followed by the same letter are not significantly different at the 0.05 level according to Tukey's HSD test concentration, there was a statistically significant difference between $\mathrm{P} 1$ and $\mathrm{P} 2$ treatments. For example, at $10^{2}$ conidia/ $\mathrm{ml}, F=15.9 ; \mathrm{df}=1.4 ; p=0.016 ;$ At $10^{9}$ conidia $/ \mathrm{ml}, F=32.8$; $\mathrm{df}=1.4 ; p=0.005$ (Table 1). The concentration/time-mortality responses for each strain were fitted to regression lines, and the respective median lethal concentration and time values were obtained using the Probit analysis (Table 2). For all the regression lines, the chi-squared values were non-significant $(p>0.05)$, indicating a good fit of the regressions. At day 5 post-applications, the median lethal concentration of P1 was 10 times higher than that of P2 $\left(1.22 \times 10^{5}\right.$ and $1.21 \times 10^{4}$ conidia $/ \mathrm{ml}$, respectively). Moreover, at a concentration of $10^{5}$ conidia $/ \mathrm{ml}$, the median lethal times were 5.8 days and only 1.03 day for P1 and P2, respectively (Table 2). The lower median lethal concentration and time found with P2 conidia treatment indicated the higher virulence of this strain towards
T. absoluta larvae than P1. This is the first study showing such efficiency of $B$. bassiana in controlling $T$. absoluta, reaching $96.7 \%$ of larval mortality using topical application of P2 strain $\left(10^{9}\right.$ conidia $\left./ \mathrm{ml}\right)$.

Pires et al. (2010) evaluated the entomopathogenic action of five B. bassiana isolates against eggs and larvae of T. absoluta. The tested isolates were pathogenic to eggs and larvae with a higher effect on eggs. However, the total mortality of the first instar larvae treated by the most virulent isolate of Beauveria $\left(10^{7}\right.$ conidia $\left./ \mathrm{ml}\right)$ reached no more than $37 \%$ by the end of the period of larval development. The same report showed higher larval mortality using $M$. anisopliae conidia at the same concentration, reaching $56 \%$. Later, Inanli et al. (2012) found B. bassiana and M. anisopliae strains pathogenic on the first larval stage of T. absoluta with mortality of 12.5 and $91.67 \%$, respectively, 9 days after application.

Table 2 Median lethal concentration $\left(\mathrm{LC}_{50}\right)$ and time $\left(\mathrm{LT}_{50}\right)$ values following treatment of $T$. absoluta larvae with $\mathrm{P} 1$ and $\mathrm{P} 2$ conidia

\begin{tabular}{|c|c|c|c|c|c|c|c|c|}
\hline \multirow[t]{2}{*}{ Strain } & \multicolumn{4}{|c|}{$\mathrm{LC}_{50}$ values (conidia/ml) calculated after 5 days of treatment } & \multicolumn{4}{|c|}{$\mathrm{LT}_{50}$ values (days) using $10^{5}$ conidia $/ \mathrm{ml}$} \\
\hline & $\mathrm{LC}_{50}(95 \% \mathrm{FL})$ & Slopes & Chi-square & $p$ value & $\mathrm{LT}_{50}(95 \% \mathrm{FL})$ & Slopes & Chi-square & $p$ value \\
\hline $\mathrm{P} 1$ & $1.22 \times 10^{5}\left(6.12 \times 10^{4}-2.24 \times 10^{5}\right)$ & $0.4994 \pm 0.062$ & 0.052 & 0.974 & $5.8(3.79-21.55)$ & $0.8656 \pm 0.2561$ & 0.033 & 0.984 \\
\hline $\mathrm{P} 2$ & $1.21 \times 10^{4}\left(5.54 \times 10^{3}-2.3 \times 10^{4}\right)$ & $0.4480 \pm 0.0474$ & 2.133 & 0.545 & $1.03(0.17-1.64)$ & $0.7235 \pm 0.2501$ & 0.200 & 0.905 \\
\hline
\end{tabular}

Fiducial limits, Probit analysis parameters and statistical analysis were included for each value 
Higher efficiency was shown by Shalaby et al. (2013): total larval mortality reached about $70 \%$ when T. absoluta larvae were fed with leaves treated with $B$. bassiana.

In general, 5 to 10 days are required to kill an insect pest after application of a mycopesticide (Quesada-Moraga and Vey 2004). Increasing the speed of kill is the aim of recent researches to pursue the development of entomopathogenic fungi as commercial mycopesticides (Quesada-Moraga and Vey 2004). We showed that the death of $50.5 \%$ of T. absoluta larvae treated with $10^{5}$ conidia $/ \mathrm{ml}$ of $\mathrm{P} 2$ was recorded after only 1 day. Higher concentration of conidia $\left(8.10^{8}\right.$ conidia/ml) allowed increasing the larval mortality to 86.3 and $92.5 \%, 1$ and 2 days post-application. P1 strain exhibited lower virulence than P2; $91.3 \%$ of larval mortality could be reached 5 days post-application of $10^{9}$ conidia/ml (Table 1).

\subsection{Regulation of enzymes associated with virulence}

In this study, topical application method was used to mimic the natural mode of infection which does not require any specialized way of invasion. $B$. bassiana acts by direct penetration anywhere on the insect cuticle after the germination of conidia and the release of cuticle-degrading enzymes. Subtilisin-like serine proteases and chitinases are classified among these enzymes because they are involved in the penetration and digestion of insect cuticles; therefore, they are strongly associated with virulence (Fang et al. 2005; Fan et al. 2007; Joshi et al. 1995; Li et al. 2010). Besides, $\beta$ glucosidase, $\beta$-galactosidase, and $N$-acetylglucosaminidase activities from a strain of $B$. bassiana showed a specific activity against locusts (Quesada-Moraga and Vey 2004). For this reason, the study of secreted enzymes is an important field in research on filamentous fungi.

To find enzymatic correlation with the higher virulence of P2, we compared the production of extracellular protease, chitinase, $\beta$-glucosidase and $\beta$-galactosidase. As previously shown, $\mathrm{P} 2$ exhibited a protease activity, nine times more than P1, by day 10 (Borgi and Gargouri 2014). A high significant difference was shown over the whole period of production $(F=688.5 ; \mathrm{df}=1.4 ; p<0.001)$ (Fig. 2a). Likewise, this strain over-produced at a lesser but significant extent a chitinase activity, approximately fourfold higher than $\mathrm{P} 1(F=858.1$; $\mathrm{df}=1.4 ; p<0.001)($ Fig. $2 \mathrm{~b}) . \beta$-Galactosidase was produced at the same yield $(F=1.3 ; \mathrm{df}=1.4 ; p=0.304)$ in both strains, while P2 showed lower $\beta$-glucosidase activity than P1 $(F=36.3 ; \mathrm{df}=1.4 ; p<001)$ (Fig. $2 \mathrm{c}, \mathrm{d})$. The overexpression of protease and chitinase is well demonstrated to be associated with increased virulence of $M$. anisopliae and B. bassiana strains (Fang et al. 2005; Fan et al. 2007; St Leger et al. 1996). Obviously, the increased pathogenesis of $P 2$ strain to T. absoluta larvae is correlated with the increased levels of these enzymes.
In a previous report, we isolated the gene encoding a subtilisin-like protease (SBP) produced by P1 and P2 strains (Borgi and Gargouri 2014). Its sequence is available in GenBank with the accession no. KF562267.1. Subtilisins are among the most important determinants of entomopathogens virulence by degrading host cuticles, providing nutrition and inhibiting antimicrobial peptides (Bagga et al. 2004). These enzymes are well represented in the genomes of entomopathogenic fungi due to lineage-specific duplications (Gao et al. 2011; Li et al. 2010). It has been shown that SBP is highly homologous to subtilisins having a cuticle degrading capacity (Borgi and Gargouri 2014). Therefore, it was important to confirm if the higher virulence of $\mathrm{P} 2$ is correlated with a different SBP regulation compared to P1. The hyper-production of total extracellular protease in $\mathrm{P} 2$ might suggest an increased genic dose of the $s b p$ protease gene in this strain. Southern blot analysis with genomic DNA digested with HindIII showed that $s b p$ is a single-copy gene in both strains B. bassiana $\mathrm{P} 1$ and $\mathrm{P} 2$ (data not shown). This result implies that there is no duplication of the $s b p$ gene in the $\mathrm{P} 2$ genome. Likewise, Fang et al. (2002) showed that a cuticle-degrading endoprotease (exhibiting $99 \%$ of homology with SBP) was present as singly copy in the genome of $B$. bassiana. Instead, a transcriptional upregulation was suggested to be responsible of the protease hyper-production in $\mathrm{P} 2$ as the $s b p$ transcript level in this strain was strongly increased versus P1 (data not shown).

\subsection{Comparative extracellular proteomes of $P 1$ and $P 2$ via 2-DE/mass spectrometry analysis}

The 2-DE coupled to LC-MS/MS was used to investigate all proteins differentially expressed in P1 and P2 secretomes. This study is useful to probe hyper-production of virulenceassociated proteins, particularly to elucidate the SBP regulation at the translational level. The total extracellular proteins of $\mathrm{P} 1$ and P2 strains were fractionated using the 2-DE and 15 among the differently expressed ones were identified via mass spectrometry (Fig. 3). The comparison of the 2-DE maps revealed striking similarities. Almost all identified proteins were expressed in both strains but showed differences in abundance. The majority of these proteins are hydrolytic enzymes. The most abundant enzyme was the SBP identified in five different spots which correspond to the same molecular weight of around $30 \mathrm{kDa}$ and $\mathrm{pI}$ varying from 3 to 10 (noted SBP 1 to SBP 5). It could be hypothesized that posttranslational modification would be responsible for this electrophoretic behaviour. The most probable modification is phosphorylation as it greatly modifies the charge and faintly the weight of proteins. Only one of these isozymes, SBP 3, was equally expressed in both strains. However, the others were either exclusive to P2 (SBP 1 and SBP 4) or accumulated to significantly higher amounts in this strain compared to $\mathrm{P} 1$ 
Fig. 2 Comparison of extracellular enzymes production by $B$. bassiana $\mathrm{P} 1$ (blue) and $\mathrm{P} 2$ (red). Values represent means $\pm \mathrm{SD}$ of three determinations

\section{a}

Protease activity (U/ml)

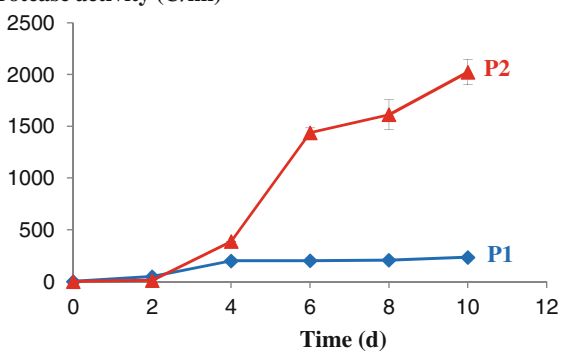

c

$\beta$-galactosidase production

$\beta$-galactosidase activity (U/ml)

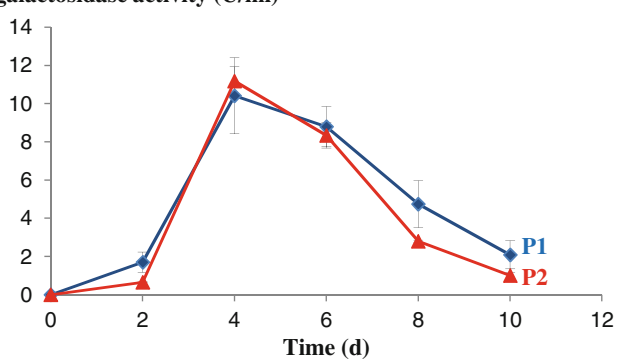

b Chitinase production

Chitinase activity $(\mathrm{mU} / \mathrm{ml})$

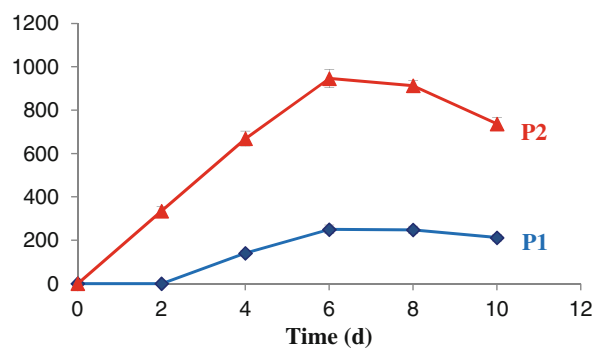

d

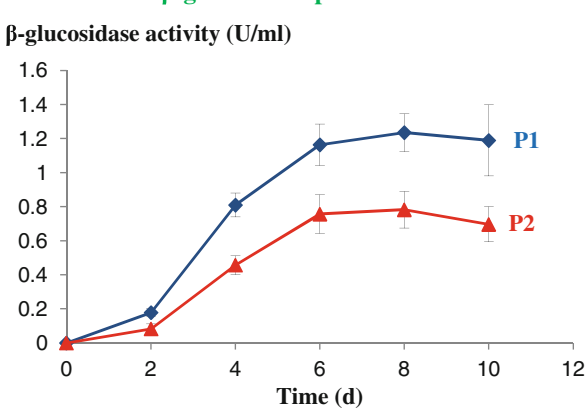

(SBP 2 and SBP 5) (Fig. 3). These results suggested that the expression of SBP in Beauveria strains is under a double control: transcriptional and post-translational. Previous reports showed the occurrence of multiple subtilisin isoforms with different $\mathrm{pI}$ values and unique N-terminal sequences in the related entomopathogenic fungi $M$ anisopliae (St Leger et al. 1994) and Verticillium chlamydosporium (Segers et al. 1999). It has been suggested that isoforms having the same molecular weight are post-translational variants or they represent gene families. Bye and Charnley (2008) found significant differences in substrate specificity and regulation of subtilisinlike proteases between isoforms of the same isolate and between different isolates of Lecanicillium spp. These isoforms, having $\mathrm{pI}$ values beween 6.48 and $>9.47$, included those sharing the same $\mathrm{N}$-terminal sequence, which may have been derived from different transcripts from a single gene or from related genes.

Recently, it has been demonstrated that the Cdc14 phosphatase has a hub role in asexual development multiple stress responses and virulence in $B$. bassiana, by regulating protein expression and many phosphorylation events (Wang et al. 2013, 2016). Phosphoproteomic analysis revealed 14 phosphorylation motifs from all the identified phosphorylation sites as potential substrates of various protein kinases targeted by Cdc14 (Wang et al. 2016). We found that 9 of these motifs exist in 14 phosphorylation sites predicted in the SBP protease sequence (GenBank accession no. KF562267.1), including 1 site SphxxE, 2 RxxTph, 1 SphP, 1 TphP, 3 RxSph, 1 RxxSph, 1 DSphxxE, 3 SphxP and 1 site TphxxP (Sph, Tph and $x$ denote a phosphorylated serine, a phosphorylated threonine

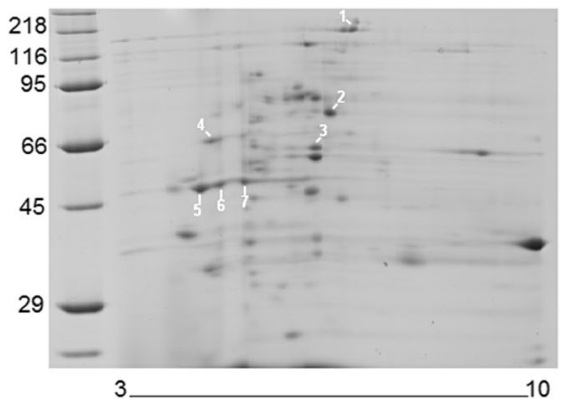

Fig. 3 Two-dimensional electrophoresis analysis. Extracellular proteins of P1 (on the left) and P2 strains (on the right). Numbers and arrows indicate the position of identified proteins. $1 \beta$-glucosidase; 2 arabinofuranosidase; 3 tripeptidyl peptidase; 4 carboxypeptidase Y; 5, 6 and 7 major allergen Mal f1; 8 carboxypeptidase $\mathrm{Y} ; 9 \alpha$-amylase; and 10 chitinase. Arrows from 11 to 15 denote SBP protease isoforms, named

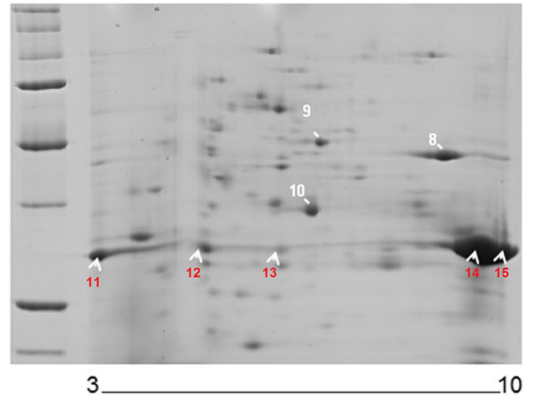

SBP 1 to SBP 5, respectively. Proteins from 1 to 8 and from 9 to 15 are upregulated in P1 and P2, respectively, except for 13 which is expressed at the same level in both strains. The $\mathrm{pH}$ range is indicated below the gel. Molecular weight marker in kilodalton is loaded on the left. This experiment was repeated three times 
and a random amino acid residue, respectively). However, neither expression regulation nor phosphorylation of Pr1 proteases has been detected as events associated with $\mathrm{Cdc14}$ in the study of Wang et al. (2016). This could be due to the time chosen by these authors (3-day-old culture samples) which was so early to identify all differently regulated proteins in fungi, especially post-translational modifications such phosphorylation of extracellular proteins, as suggested by the authors.

Figure 3 shows that a chitinase, a carboxypeptidase $Y$ (spot 8 ) and an $\alpha$-amylase were equally present in higher quantities in P2 strain. In P1 strain, four enzymes were found upregulated which are a $\beta$-glucosidase, an arabinofuranosidase, a carboxypeptidase Y (spot 4) and a tripeptidyl peptidase. Two isoforms of the major allergen Mal $\mathrm{fl}$ were exclusive to P1 and another was over-expressed compared to P2.

A previous study showed by comparative transcriptome analysis that growth in culture containing insect cuticles does not mimic the environment experienced on the insect surfaces. Secreted proteins, particularly proteases, were highly more induced on insect cuticle surfaces (Gao et al. 2011). As the experiments of this study were performed in vitro, further experimentation is required to demonstrate the production, accumulation and localization of individual SBP protease isoforms and chitinase in insects during infection processes.

\section{Conclusion}

Difficulty in managing the tomato borer led to the spread of this dangerous specie in most of the countries, threatening the current world tomato production. Mycoinsecticides are among the best choices to control this pest. Here, we showed a high insecticidal potential of $B$. bassiana $\mathrm{P} 1$ and $\mathrm{P} 2$ strains towards T. absoluta larvae and significant better efficiency of $\mathrm{P} 2$ than $\mathrm{P} 1$. This allows the recommendation of $\mathrm{P} 2$ for the application in the management of the tomato borer. P2 is a mutant hyperproducer of extracellular proteases and chitinase, compared to the wild-type strain P1. We have identified four isoforms of the SBP, which were over-expressed in P2. Differently expressed isoforms were suggested to be the result of different transcriptional and translational regulation in both strains, and this might explain the higher virulence of P2 towards T. absoluta. These results showed that the profile of fungal extracellular enzymes, especially proteases, could be considered as a fingerprint reflecting pathogenicity towards insects; enzymatic assays may contribute to the screening of the most virulent strains.

Acknowledgments This work was undertaken and funded in the frame of our contract with the Ministry of Higher Education and Scientific Research, Tunisia.
Compliance with ethical standards

Conflict of interest The authors that they have no conflict of interest.

\section{References}

Abbott WS (1925) A method of computing the effectiveness of an insecticide. J Econ Entomol. doi:10.1093/jee/18.2.265a

Bagga S, Hu G, Screen SE, St Leger RJ (2004) Reconstructing the diversification of subtilisins in the pathogenic fungus Metarhizium anisopliae. Gene. doi:10.1016/j.gene.2003.09.031

Borgi I, Gargouri A (2014) Investigations on a hyper-proteolytic mutant of Beauveria bassiana: broad substrate specificity and high biotechnological potential of a serine protease. FEMS Microbiol Lett. doi:10.1111/1574-6968.12339

Bye NJ, Charnley AK (2008) Regulation of cuticle-degrading subtilisin proteases from the entomopathogenic fungi, Lecanicillium spp: implications for host specificity. Arch Microbiol. doi:10.1007/s00203007-0296-8

Campos MR, Rodrigues ARS, Silva WM, Silva TBM, Silva VRF, Guedes RNC, Siqueira HAA (2014) Spinosad and the tomato borer Tuta absoluta: a bioinsecticide, an invasive pest threat, and high insecticide resistance. PLoS One. doi:10.1371/journal.pone.0103235

Fan Y, Fang W, Guo S, Pei X, Zhang Y, Xiao Y, D L, Jin K, Bidochka MJ, Pei Y (2007) Increased insect virulence in Beauveria bassiana strains overexpressing an engineered chitinase. Appl Environ Microbiol. doi:10.1128/AEM.01974-06

Fang W, Zhang Y, Yang X, Wang Z, Pei Y (2002) Cloning and characterization of cuticle degrading enzyme CDEP-1 from Beauveria bassiana. Yi Chuan Xue Bao 29:278-282

Fang W, Leng B, Xiao Y, Jin K, J M, Fan Y, Feng J, Yang X, Zhang Y, Pei Y (2005) Cloning of Beauveria bassiana chitinase gene Bbchit1 and its application to improve fungal strain virulence. Appl Environ Microbiol. doi:10.1128/AEM.71.1.363-370.2005

Faria M, Wraight SP (2007) Mycoinsecticides and mycoacaricides: a comprehensive list with worldwide coverage and international classification of formulation types. Biol Control. doi:10.1016/j. biocontrol.2007.08.001

Gao Q, Jin K, Ying S-H, Zhang Y, Xiao G, Shang Y, Duan Z, Hu X, Xie X-Q, Zhou G, Peng G, Luo Z, Huang W, Wang B, Fang W, Wang S, Zhong Y, Ma L-J, St Leger RJ, Zhao G-P, Pei Y, Feng M-G, Xia Y, Wang C (2011) Genome sequencing and comparative transcriptomics of the model entomopathogenic fungi Metarhizium anisopliae and M. acridum. PLoS Genet. doi:10.1371/journal.pgen.1001264

Giustolin TA, Vendramim JD, Alves SB, Vieira SA (2001) Pathogenicity of Beauveria bassiana (Bals.) Vuill. to Tuta absoluta (Meyrick) (Lepidoptera: Gelechiidae) reared on two genotypes of tomato. Neotrop Entomol. doi:10.1590/S1519-566X2001000300013

González-Cabrera J, Mollá O, Montón H, Urbaneja A (2011) Efficacy of Bacillus thuringiensis (Berliner) in controlling the tomato borer, Tuta absoluta (Meyrick) (Lepidoptera: Gelechiidae). BioControl. doi:10.1007/s10526-010-9310-1

Inanli C, Yoldas Z, Birgücü AK (2012) Effects of entomopathogenic fungi, Beauveria bassiana (Bals.) and Metarhizium anisopliae (Metsch.) on larvae and egg stages of Tuta absoluta (Meyrick) (Lepidoptera: Gelechiidae). Ege Üniversitesi Ziraat Fakültesi Dergisi 49: 239-242

Joshi L, St Leger RJ, Bidochka MJ (1995) Cloning of a cuticle degrading protease from the entomopathogenic fungus, Beauveria bassiana. FEMS Microbiol Lett. doi:10.1111/j.1574-6968.1995.tb07360.x 
Kembhavi AA, Kulharni A, Pant AA (1993) Salt-tolerant and thermostable alkaline protease from Bacillus subtilis NCIM no 64. Appl Biochem Biotechnol. doi:10.1007/BF02916414

Kim K-J, Yang Y-J (2003) Purification and characterization of chitinase from Streptomyces sp. M-20. J Biochem Mol Biol. doi:10.5483/ BMBRep.2003.36.2.185

Klieber J, Reineke A (2015) The entomopathogen Beauveria bassiana has epiphytic and endophytic activity against the tomato leaf miner Tuta absoluta. J Appl Entomol. doi:10.1111/jen.12287

Kunst A, Draeger B, Ziegernhorn J (1988) Colorimetric methods with glucose oxidase and peroxidase. In: Bergmeyer HU, Bergmeyer J, Grassl M (eds) Methods of enzymatic analysis, 3rd edn. VCH Publishers, Weinheim, Ger, pp. 178-185

Laemmli UK (1970) Cleavage of structural proteins during the assembly of the head of bacteriophage T4. Nature. doi:10.1038/227680a0

Li J, Yu L, Yang J, Dong L, Tian B, Yu Z, Liang L, Zhang Y, Wang X, Zhang K (2010) New insights into the evolution of subtilisin-like serine protease genes in Pezizomycotina. BMC Evol Biol. doi:10.1186/1471-2148-10-68

Nguyen T-H, Splechtna B, Steinböck M, Kneifel W, Lettner HP, Kulbe KD, Haltrich D (2006) Purification and characterization of two novel $\beta$-galactosidases from Lactobacillus reuteri. J Agric Food Chem. doi:10.1021/jf053126u

Ortiz-Urquiza A, Riveiro-Miranda L, Santiago-Álvarez C, QuesadaMoraga E (2010) Insect-toxic secreted proteins and virulence of the entomopathogenic fungus Beauveria bassiana. J Invertebr Pathol. doi:10.1016/j.jip.2010.07.003

Pires LM, Marques JE, Oliveira VJ, Ahmed SB (2010) Selection of isolates of entomopathogenic fungi for controlling Tuta absoluta (Meyrick) (Lepidoptera: Gelechiidae) and their compatibility with insecticides used in tomato crop. Neotrop Entomol. doi:10.1590/ S1519-566X2010000600020

Pratissoli D, Parra JRP (2000) Fertility life table of Trichogramma pretiosum (Hym., Trichogrammatidae) in eggs of Tuta absoluta and Phthorimaea operculella (Lep., Gelechiidae) at different temperatures. J Appl Ent. doi:10.1046/j.1439-0418.2000.00477.x

Quesada-Moraga E, Vey A (2004) Bassiacridin, a protein toxic for locusts secreted by the entomopathogenic fungus Beauveria bassiana. Mycol Res. doi:10.1017/S0953756204009724

Saibi W, Gargouri A (2011) Purification and biochemical characterization of an atypical $\beta$-glucosidase from Stachybotrys microspora. J Mol Catal B. doi:10.1016/j.molcatb.2011.05.007
Segers R, Butt TM, Carder JH, Keen JN, Kerry BR, Peberdy JF (1999) The subtilisins of fungal pathogens of insects, nematodes and plants: distribution and variation. Mycol Res. doi:10.1017/ S0953756298007345

Shalaby HH, Faragalla FH, El-Saadany HM, Ibrahim AA (2013) Efficacy of three entomopathogenic agents for control the tomato borer, Tuta absoluta (Meyrick) (Lepidoptera: Gelechiidae. Nat Sci 11:63

Siqueira HQA, Guedes RNC, Picanco MC (2000) Insecticide resistance in populations of Tuta absoluta. Agric For Entomol. doi:10.1046/ j.1461-9563.2000.00062.x

SPSS Version 16.0 for Windows 2008. SPSS Inc., Chicago

St Leger RJ, Bidochka MJ, Roberts DW (1994) Isoforms of the cuticle degrading Prl protease and production of a metalloproteinase by Metarhizium anisopliae. Arch Biochem Biophys. doi:10.1006/ abbi.1994.1350

St Leger RJ, Joshi L, Bidochka MJ, Roberts DW (1996) Construction of an improved mycoinsecticide overexpressing a toxic protease. Proc Natl Acad Sci U S A. doi:10.1073/pnas.93.13.6349

Vizcaín JA, Deutsc EW, Wan R, Csorda A, Reisinge F, Río D, Diane JA, $\mathrm{Su}$ Z, Farra T, Bandeir N, Biz PA, Xenarios I, Eisenacher M, Mayer G, Gatto L, Campos A, Chalkley RJ, Kraus HJ, Albar JP, MartinezBartolomé S, Apweiler R, Omenn GS, Martens L, Jones AR, Hermjakob H (2014) ProteomeXchange provides globally coordinated proteomics data submission and dissemination. Nature Biotechnol. doi:10.1038/nbt.2839

Wang J, Liu J, Hu Y, Ying S-H, Feng M-G (2013) Cytokinesis-required Cdc14 is a signaling hub of asexual development and multi-stress tolerance in Beauveria bassiana. Sci Rep. doi:10.1038/srep03086

Wang Z-K, Wang J, Liu J, Ying S-H, Peng X-J, Feng M-G (2016) Proteomic and phosphoproteomic insights into a signaling hub role for Cdc14 in asexual development and multiple stress responses in Beauveria bassiana. PLoS One. doi:10.1371/journal.pone.0153007

Zappala L, Biondi A, Alma A, Al-Jboory IJ, Arno J, Bayram A, Chailleux A, El-Arnaouty A, Gerling D, Guenaoui Y, Shaltiel-Harpaz L, Siscaro G, Stavrinides M, Tavella L, Aznar, RV, Urbaneja A, Desneux N (2013) Natural enemies of the South American moth, Tuta absoluta, in Europe, North Africa and Middle East, and their potential use in pest control strategies. J Pest Sci. doi: 10.1007/ s10340-013-0531-9 